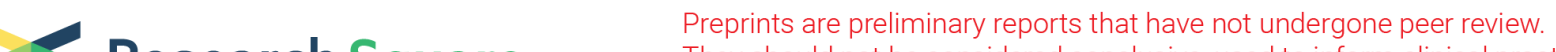 $\begin{array}{ll}\text { Research Square } & \text { They should not be considered conclusive, used to inform clinical practice, } \\ \text { or referenced by the media as validated information. }\end{array}$
}

\section{Mechanism of Moisture Adsorption In Plant Fibers Surface-Modified With Glycerol Evaluated By LF- NMR Relaxation Technique}

\section{Lili Fu}

ZTRI: China National Tobacco Corp Zhengzhou Tobacco Research Institute

\section{Ke Zhang}

ZTRI: China National Tobacco Corp Zhengzhou Tobacco Research Institute

\section{Mingjian Zhang}

ZTRI: China National Tobacco Corp Zhengzhou Tobacco Research Institute

\section{Le Wang}

ZTRI: China National Tobacco Corp Zhengzhou Tobacco Research Institute

\section{Songjin Zheng}

China Tobacco Hebei Industrial Co Ltd

\section{Ze Liu}

China Tobacco Yunnan Industrial Co Ltd

\section{Shanzhai Shang}

China Tobacco Yunnan Industrial Co Ltd

\section{Yue Sun}

ZTRI: China National Tobacco Corp Zhengzhou Tobacco Research Institute

\section{Feng Huang}

ZTRI: China National Tobacco Corp Zhengzhou Tobacco Research Institute

\section{Shuang Wang}

ZTRI: China National Tobacco Corp Zhengzhou Tobacco Research Institute

\section{Qi Zhang}

ZTRI: China National Tobacco Corp Zhengzhou Tobacco Research Institute

\section{Bing Wang}

ZTRI: China National Tobacco Corp Zhengzhou Tobacco Research Institute

\section{Bin Li}

ZTRI: China National Tobacco Corp Zhengzhou Tobacco Research Institute

\section{Yan Cao}

Guangzhou Institute of Energy Conversion

\section{Zhongya Guo ( $\nabla$ zhongyaguo@126.com )}

ZTRI: China National Tobacco Corp Zhengzhou Tobacco Research Institute https://orcid.org/00000001-8160-4866 


\section{Research Article}

Keywords: Moisture transfer, Plant fiber, LF-NMR relaxation technique, Water state and distribution

Posted Date: September 16th, 2021

DOl: https://doi.org/10.21203/rs.3.rs-860149/v1

License: (c) (i) This work is licensed under a Creative Commons Attribution 4.0 International License. Read Full License

Version of Record: A version of this preprint was published at Cellulose on February 4th, 2022. See the published version at https://doi.org/10.1007/s10570-022-04449-1. 


\section{Abstract}

Surface modification by humectants is an important technology to improve product quality in textile field, healthcare, tobacco processing and paper-making industry. As a common humectant glycerol is applied to keep the moisture adsorbability of plant fibers during manufacturing. The effects of glycerol on the moisture adsorption of plant fibers were studied by analysising the induced differences of bulk and surface physicochemical property with XRD, FTIR, SEM characterizations. The improvement of moisture adsorption capacity of the modified plant fibers was due to the increased active adsorption sites, while the moisture diffusion resistance increased simultaneously with glycerol indicated by a declining $D_{\text {eff. }}$ LFNMR relaxation spectra demonstrated the water sates and distributions in plant fibers were changed by loading glycerol. The moisture transfer mechanisms induced by glycerol were also investigated. Free water failed to materialize in the plant fibers treated with glycerol, immobile water existed preferentially during the adsorption, and bound water presented increasing after the immobile water were saturated. These findings are useful to improve the manufacturing processes of moisture-retaining properties of different functional plant fibers.

\section{Introduction}

Plant fibers contain major components of cellulose (linear glucose molecules) and hemicellulose (heteroglycans) and lignin (Pei and Ping 2012). Because of rich hydrophilic functional groups of the former two components (Jiang et al. 2017; Hofstetter et al. 2006), plant fibers present strong hydrophilic properties. Water adsorption capability of plant fibers is closely related to their properties, such as mechanical strength (Perrier et al. 2017; Ridzuan et al. 2016), physicochemical resistance (Varara et al. 2017), bacterial inhibition capability (Popescu et al. 2014), hydrolysis (Jiang et al. 2021) and pyrolysis performance (Sun et al. 2019). Therefore, water adsorption behaviour on plant fibers are importantly correlated to their wide applications, such as fields of paper-making (Modaressi and Garnier 2002), bioenergy (Emerson et al. 2018; Sotannde et al. 2020), bio-degradation (Gheorghita et al. 2020), functional materials (Hachem et al. 2020; Melo et al. 2021), pharmaceutics, cosmetics, textile and tobacco industries (Sun et al. 2019).

The moisture adsorption performances of plant fibers are mainly affected by hydrophilic compositions, microstructures and surface morphologies (Penttilä et al. 2020; Jiang et al. 2021), which can be changed by a multiple physiochemical methods and techniques.

Researchers have investigated on the surface modification with humectants to optimize the moisture adsorption property and strengthen the water holding capacity (WHC) of plant fibers (Jiang et al, 2021; Yamamoto et al. 2020). Among of them, glycerol is commonly applied as a humectant in textile field, healthcare, tobacco processing and paper-making industry. For example, a sheet surface of plant fibers coated with a high spreading rate (20-30\%, $80 \%$ of the coating liquid being glycerol) is used for producing ultra-soft moisture tissue towel paper with outstanding features of hydrophilicity, excellent softness and skin-friendliness for newborns and other special populations. In tobacco industry, glycerol is 
usually used as a humectant added to heated tobacco substrate to preserve moisture and to generate aerosol when heated (Yang et al. 2015; Halter and Ito 1972). Overall, investigations of mechanisms on WHC of plant fibers by glycerol optimizing were limited, given their importance and the demands for the optimization.

The moisture adsorption of plant fibers is affected by the interaction between their equilibrium adsorption capacity and transport resistance (Alak et al. 2000). Water vapor adsorption experiments could reveal the influence of glycerol on hygroscopic kinetic parameters. Low-field nuclear magnetic resonance (LF-NMR) technique has been widely used in obtaining the water state and distribution in different materials, such as fruits, vegetables, protein, woods, and other porous media. Relaxation time demonstrates variations of physical and chemical processes of the inter-facial water from the perspective of molecular structure. Two-dimensional time domain LF-NMR (2D LF-NMR) technique (Guo et al. 2019; Wang et al. 2020b; Montrazi et al. 2018; Zheng et al. 2017) combining two sequences between longitudinal (lattice-spin relaxation time, $\left.T_{1}\right)$ and transverse (the spin-spin relaxation time, $T_{2}$ ) relaxation time $\left(T_{1}-T_{2}\right)$ simultaneously has been developed. Among the parameters, $T_{1}$ is the time for the hydrogen protons to relapse to the original energy stage while the additional pulse electromagnetic wave is removed, and $T_{2}$ is the time for the actuated hydrogen protons in the identical frequency but different moving tends to change their directions at the same level (Joardder et al. 2019; Wang et al. 2020a). The sequence for capturing $T_{1}$ data is encoded in the indirect dimension, while that for $T_{2}$ is modulated by the direct dimension. Inversion-Recovery (IR) and Saturation-Recovery (SR) are encoded in the indirect dimension for $T_{1}$, and encoded in the combination with Carr-Purcell-Meiboom-Gill (CPMG) for $T_{2}$. Thus, protons can be distinguished to several components by the value of their relaxation time in samples, leading to the capture and visualization of existing state and distribution of water in samples during the water vapor adsorption (Sanders et al. 2021).

Although the moisture adsorption of the porous media has been studied for more than a century, researchers have not reached a consensus on the mechanism of the water migration (Popescu et al. 2014; Hill et al. 2009) and proposed numerous adsorption mechanisms (Fredriksson and Thybring 2018; Guo et al. 2017; Lovikka et al. 2018; Zhang et al. 2018), such as the moisture transfer process via the mono-layer adsorption, the muti-layer adsorption or the capillary condensation upon the increased relative humidity, parallel exponential kinetics. This work applied the advanced and insightful 2D LF-NMR technique and other characterization methods, to study the water state and distribution and further the structure and surface of plant fibers loaded with different amounts of glycerol. In the water vapor adsorption experiment, the influence of glycerol on hygroscopic kinetic parameters was revealed. The collected information was aimed to provide the establishment of mechanisms on the moisture migration in plant fibers.

\section{Materials And Methods Samples preparation}


In this study, a plant fiber sheet (coded as ZZP0) is produced by China Tobacco Yunnan Reconstituted Tobacco Co. Ltd. ZZP0, plant-sourced material consisted of wood pulp and hemp pulp at $90-98 \%$ to 2$10 \%$, and the ratios of cellulose, hemicellulose and lignin are $52.8 \%, 30.5 \%$ and $16.8 \%$ respectively. ZZPO exhibits paper structure with a finished the surface density of $45 \pm 0.5 \mathrm{~g} / \mathrm{m}^{2}$.

This sample was subjected to post-treatments using a set of self-designed devices to impregnate glycerol first and followed by a two-stage infrared drying process (Fig. 1). The impregnation liquid was made of glycerol-ethanol solution, and the two-stage infrared was at conducted at $50{ }^{\circ} \mathrm{C}$ and $80{ }^{\circ} \mathrm{C}$ in order.

The composite sheet samples loaded with different glycerol contents were coded as ZZP1, ZZP2 and ZZP3. They were obtained by adjusting the concentration of the applied impregnation liquid. Glycerol contents in the materials were analyzed by gas chromatography (GC 6890, Agilent Technologies, Inc. US). The information of the starting ZZP0 and its post-treatment samples ZZP1, ZZP2 and ZZP3 is given in Table 1.

Table 1

Information of the plant fiber samples ${ }^{\dagger}$

\begin{tabular}{|c|c|c|c|c|}
\hline \multirow[t]{2}{*}{ sample } & \multicolumn{2}{|c|}{ Preparation condition } & \multirow[t]{2}{*}{ wt. (\%) } & \multirow{2}{*}{$L^{\prime}(\mathrm{mm})$} \\
\hline & $c_{i s}(\mathrm{~mol} / \mathrm{L})$ & $t_{i}(\min )$ & & \\
\hline ZZPO & / & / & 0.00 & 0.120 \\
\hline ZZP1 & 0.20 & 1 & 5.60 & 0.131 \\
\hline ZZP2 & 0.60 & 5 & 14.12 & 0.135 \\
\hline ZZP3 & 1.00 & 5 & 21.02 & 0.137 \\
\hline
\end{tabular}

Besides all of the samples were used during the water vapor adsorption, characterization and LF-NMR T2 relaxation spectra, ZZP0 and ZZP3 were applied for capturing 2D LF-NMR T1-T2 relaxation spectra. Each sample sheet was cut into $0.5 \times 0.5 \mathrm{~cm}$ in size for the subsequent characterizations and experiments except for the air permeability measurement.

\section{Water vapor adsorption experiment}

The moisture adsorption properties of the prepared samples were measured using a water vapor sorption kit called SPSx-1 $\mu$ Advance (ProUmid GmbH \& Co. KG, Germany). Samples were placed on its sample holder that was connected to a microbalance under a hanging wire. The holder was located in a thermostatically controlled chamber, which provides a stable hygrothermal environment (Alak et al. 2000; Guo et al. 2017). Prior to the water vapor adsorption of plant fiber samples at a specific condition of 25 
${ }^{\circ} \mathrm{C}$ and $80 \% \mathrm{RH}$ (relative humidity), samples were conditioned at $25{ }^{\circ} \mathrm{C}$ and $0 \% \mathrm{RH}$ for $24 \mathrm{~h}$. The judgement of the adsorption equilibrium was that the rate of the sample mass change was below 0.2 $\mathrm{mg} / 20 \mathrm{~min}$.

In this work, the moisture content $(M C)$ was the water content on dry weight base, and the calculation of moisture ratio (MR) of each sample followed the Eq. (1) (Chen et al. 2012):

$$
M R=\frac{M C_{e}-M C_{\mathrm{t}}}{M C_{e}-M C_{0}}
$$

where $M C_{t}$ is the real-time $(t, \mathrm{~s})$ moisture content (\%), $M C_{0}$ is the initial moisture content $(\%)$, and $M C_{\mathrm{e}}$ is the equilibrium adsorption moisture content (\%).

The equation Eq. (2) below, based on Fick's Second Law of diffusion was applied for the calculation of the effective diffusivity of the samples (Chen et al. 2012). $D_{\text {eff }}$ was determined by the slope of the straight line of experimental adsorption data in terms of $L n(M R)$ vs. adsorption time, whereas the $M R$ value $\geq$ 0.05 was applicable to fit the line.

$$
\ln (M R)=\ln \left(\frac{8}{\pi^{2}}\right)-\left(\frac{\pi^{2} D_{e f f}}{4 L^{2}} t\right)
$$

where $t$ is adsorption time $(\mathrm{s}), L$ is the half thickness of the sample $(\mathrm{m}), D_{\text {eff }}$ is the diffusion coefficient $\left(\mathrm{m}^{2} / \mathrm{s}\right)$.

To capture the adsorption isotherms of the samples before and after loading with glycerol, the dynamic vapor sorption (single cycle adsorption-desorption) was carried out by SPSx-1 $\mu$ Advance (Hill et al. 2010; Fredriksson and Thybring 2018; Guo et al. 2017) at $25^{\circ} \mathrm{C}$. The wide $\mathrm{RH}$ range was from 0 to $95 \%$, and the judgement of the adsorption equilibrium for the target $\mathrm{RH}$ was consistent as mentioned above.

\section{Sample characterizations}

Crystal structures of the plant fibers with the loaded glycerol was explored using a X-ray diffractometry (D8 Advance, Bruker Corporation, Germany), the laboratory X-ray generator operating in reflection mode. The maximum power, tube voltage and electric current of the X-ray emitter were $3 \mathrm{KW}, 40 \mathrm{KV}$ and $40 \mathrm{~mA}$, respectively. The sample holder is made of single crystal silicon ( $20 \mathrm{~mm}$ diameter, $0.5 \mathrm{~mm}$ thickness), the scanning angle $2 \theta$ ranged from $5^{\circ}$ to $50^{\circ}$, and all $2 \theta$ values are from Cu Ka radiation. ZZPO is made from wood and hemp pulp, and exhibiting paper structure, to avoid the the effect of ball milling on the crystallinity index (Crl) of the samples, all sample sheet was cut into pieces $0.5 \times 0.5 \mathrm{~mm}$ in size for this characterization. Surface functional groups of samples were determined using a FTIR spectroscopy (IS 50 , Thermo Scientific Nicolet, USA). The spectra were recorded in the range of $400-4000 \mathrm{~cm}^{-1}$ and each spectrum was the result of 32 accumulated scans with $4 \mathrm{~cm}^{-1}$ resolution. The pore characteristics of the samples were investigated by a mercury intrusion porosimetry (MIP) (AutoPore IV 9500, Micromeritics Instrument Corporation, US). The observation was carried after the samples underwent drying process at 
$80^{\circ} \mathrm{C}, 2 \mathrm{~h}$. Air permeability was analyzed by an air permeability tester (TQY-4A, Hefei Institutes of Physical Science, China Academy of Sciences, China). Morphology and composition spectral analysis on the samples were observed by a field emission scanning electron microscopy (SEM, ZEISS Sigma 300, Carl Zeiss AG, Germany) operating at $20.0 \mathrm{kV}$. Each sample was mounted on a sample holder with the carbon conductive tape and coated with a thin layer of platinum using a sputter coater.

The water state and distribution in the samples were performed using a LF-NMR analyzer (NMI20-040V-I, Shanghai Niumag Co., Ltd, China), equipped with a $0.55 \mathrm{~T}$ permanent magnet corresponding to a proton resonance frequency of $22.4 \mathrm{MHz}$ at $30^{\circ} \mathrm{C}$. 2D LF-NMR T $\mathrm{T}_{1} \mathrm{~T}_{2}$ relaxation spectra on ZZP0 and ZZP3 were collected based on the SR-CPMG sequence in a Teflon sample tube ( $440 \mathrm{~mm}$, internal diameter). To increase the ratio of signal-to-noise $(\mathrm{S} / \mathrm{N})$, the relaxation data were measured from 2000 echoes with $9 \mu \mathrm{s}$ and $25 \mu$ s for $90^{\circ}$ and $180^{\circ}$ pulses respectively. Other test parameters included: 0.1 ms for echo time, 10 $\mathrm{dB}$ and $3 \mathrm{~dB}$ for analog gain and the digital gain respectively, 32 for the number of repeat scanning (NS), $1000 \mathrm{~ms}$ for waiting time (TW), $200 \mathrm{KHz}$ for sampling frequency (SW). $\mathrm{T}_{2}$ relaxation spectra were collected based on the CPMG pulse sequence. The parameter setting was consistent to the 2D LF-NMR $\mathrm{T}_{1}-\mathrm{T}_{2}$ relaxation spectra test above. Multi-Explnv analysis software (Shanghai Niumag Co., Ltd, China) was applied during the signal value inversion.

\section{Results And Discussion}

\section{Water vapor adsorption dynamics of plant fibers}

Water vapor adsorption experiments were conducted at $25{ }^{\circ} \mathrm{C}$ and $80 \% \mathrm{RH}$, and the moisture adsorption curves of the experimental samples were shown in Fig. 2a. It exhibited the corresponding increase of $M C_{e}$ with the increasing content of glycerol, evidenced by $14.22 \%, 19.64 \%, 25.03 \%$, and $34.41 \%$ for ZZP0, ZZP1, ZZP2 and ZZP3, respectively. The prolonged hygroscopic equilibrium time was another marker by the increased application content of glycerol, evidenced by that $8.38 \mathrm{~h}$ for ZZP0, and $18.37 \mathrm{~h}$ for ZZP3 (2.19 times). According to Eq. (2), the adjusted R-square of the fitting line correlating $\operatorname{Ln}(M R)$ and the time was greater than 0.994 for each sample (Fig. 2b). The calculated $D_{\text {eff }}$ values were $1.841 \times 10^{-13} \mathrm{~m}^{2} / \mathrm{s}$, $1.565 \times 10^{-13} \mathrm{~m}^{2} / \mathrm{s}, 1.391 \times 10^{-13} \mathrm{~m}^{2} / \mathrm{s}$ and $1.255 \times 10^{-13} \mathrm{~m}^{2} / \mathrm{s}$ for ZZP0, ZZP1, ZZP2 and ZZP3, respectively, revealing a decrease of $D_{\text {eff }}$ upon the increased application of glycerol. The moisture capacity strengthened on the contrary to $D_{\text {eff }}$ of the same plant fibers. Fig. $S 1$ displayed the $M C_{e}$ of the samples enhanced with the increase of glycerol especially at higher than $60 \% \mathrm{RH}$. According to the International Union of Pure and Applied Chemistry (IUPAC) classification, as shown in Fig. S1a, the

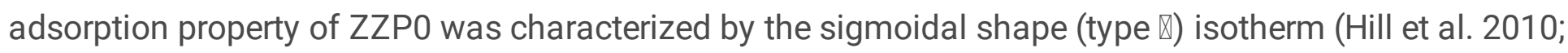
Popescu et al. 2014) and an absolute hysteresis was observed around $80 \% \mathrm{RH}$ (Hill et al. 2010). In

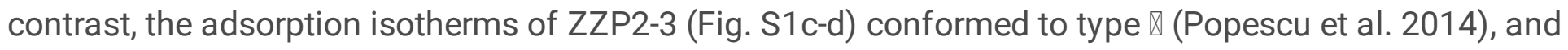
the hysteresis phenomenon barely existed for ZZP2-3. It verified that the added glycerol as a humectant changed the adsorption property of the plant fiber. The variation trend of these adsorption isotherms illustrated the interaction mechanisms between water vapor and the samples were changed, that 
reversible formation of hydrogen bonding occurred during the moisture adsorption for the plant fiber with glycerol was concluded (Hill et al. 2010).

The water vapor adsorption performance of the plant fibers could be mainly ascribed to the distributed adsorption sites, as amorphism region (Garg et al. 2021), hydrophilic functional groups, etc, and the diffusion resistance associated with the pore characteristics and permeability (Jiang et al. 2017).

As a major component of the plant fibers, cellulose contains a crystalline structure with intra- and intermolecular hydroxyl groups (Dereka, et al. 2021). Water molecules on the plant fibers are linked to their amorphism region by the hydrogen bond. Figure 3 shows XRD patterns of all the prepared glycerol-loaded samples. The background signal including the sample holder and basal signal should be subtracted from XRD data to optimize the fitting progress, and this measure could ensure a stable baseline fitting, demonstrating the XRD patterns with nearly zero intensity at $30^{\circ} 2 \theta$ (Fig. 3). The XRD curves of these samples presented that Miller indices of (1-10), (110) and (200) peaks located at about $15.04^{\circ}, 16.04^{\circ}$ and $22.49^{\circ} 2 \theta$ respectively, which could be the main contributors of the diffraction intensity and exhibited cellulose $\otimes$ (French, 2014; Wang et al. 2016). Additionally, the indices of (011) and (012) for the peaks at about $12.16^{\circ}$ and $20.34^{\circ} 2 \theta$ respectively indicated the presence of cellulose $\otimes$ (French, 2014). Hence, ZZPO-3 would have the crystal structure of cellulose $\triangle$ and $\triangle$. The $\mathrm{Crl}$ of the experimental samples should be calculated by the integrated area ratio of deconvoluted crystalline peaks and the whole diffraction curve (French and Cintrón 2013; French 2020). Deconvolution method with Voigt function (Yao et al. 2020) representing the separate peaks associated with crystalline structures and amorphous area was proposed to analyze the $\mathrm{Crl}$ of the samples. Figure 3 showed that $\mathrm{Crl}$ decreased from $88.02-83.78 \%$ upon the increase of glycerol-loading and the $\mathrm{R}^{2}$ of the fitting for every sample was above 0.9978 . This was likely deduced to the fact that glycerol enlarged the amorphism region of the material whose crystalline structure was not affected, neither its surface morphology (see Fig. S2). The enlarged amorphism region promoted the WHC of the plant fibers.

The hydroxyl group in glycerol seemed to have contributed to the formation of hydrogen bond between the water molecule and the sample. Both the hydroxyl group and the $M C$ were positively correlated with the glycerol content during the water vapor adsorption. For example, ZZP3 had the highest glycerol content and the $M C$ value. FTIR spectroscopy could reveal the presence of organic functional groups in the plant fibers (see Fig. S3 and Table S1), especially the existence of hydrogen bonding structures which agreed with the literature on this type of materials (Bu et al. 2018). As shown in Fig. 4, the wide band at $3330 \mathrm{~cm}^{-1}$ could be attributed to -OH vibrational stretching (Bu et al. 2018; Kolbuk et al. 2020), $2900 \mathrm{~cm}^{-}$ 1 to the $-\mathrm{CH}$ stretching, $997 \mathrm{~cm}^{-1}$ to methylene $\left(-\mathrm{CH}_{2}-\right), 1051 \mathrm{~cm}^{-1}$ to methine $(\equiv \mathrm{CH})$ and $1025 \mathrm{~cm}^{-1}$ to the alcoholic hydroxyl vibration (C-OH) (Lorenzo et al. 1999), respectively. The peaks at $2900 \mathrm{~cm}^{-1}, 997$ $\mathrm{cm}^{-1}, 1051 \mathrm{~cm}^{-1}$ and $1025 \mathrm{~cm}^{-1}$ were enhanced, and the water adsorption sites (Taniguchi et al. 1978) increased due to the inter-molecular force between the plant fiber and the added glycerol according to the increase of glycerol content (Fig. 4a). ZZP3 presented a dramatic increase of $3330 \mathrm{~cm}^{-1}$ and $1647 \mathrm{~cm}^{-1}$ peak patterns after water vapor adsorption (Fig. 4b), the later attributed to the $\mathrm{H}-\mathrm{O}-\mathrm{H}$ stretching of 
absorbed water (Dereka et al. 2021), and WHC of the plant fibers was promoted due to the interaction in the water-glycerol-plant fiber system, including hydrogen bonds and adsorption site in the amorphous zones of the plant fibers, particularly the hydrogen bonds between the glycerol and water.

These findings showed that loading with glycerol extended the equilibrium time and decreased $D_{\text {eff }}$ of the plant fibers (Fig. 2). It could be deduced that outstanding moisture capacity cost longer equilibrium time during the water vapor adsorption, and the added glycerol enhanced the water transport resistance due to the change of pore characteristics (possibly pore structure, pore size or porosity) and the water permeability of the plant fibers.

According to Fig. $5 \mathrm{a}$, the samples demonstrated macroporous structure (25-75 $\mu \mathrm{m}$, dominantly) by MIP, and the loading of glycerol reduced the porosity of the plant fibers. ZZP1 indicated an obvious decline of macroporous proportion comparing to ZZP0, while the macroporous proportion of ZZP2 and ZZP3 reduced gradually comparing to ZZP1 (Fig. 5a). The porosity values were $80.32 \%, 77.83 \%, 75.88 \%$ and $67.52 \%$ for ZZP0, ZZP1, ZZP2 and ZZP3, respectively (Fig. 5b). By inference, some glycerol molecules impregnated into the macropore preferentially during the impregnation, and others possibly binded the surface of the plant fibers. Glycerol occupied part of the pore volume, and fiber layers wrapped with glycerol extended the path of water molecules in further during the water vapor adsorption. The permeability of the sample reflected the mass transport capacity of the sample (Liu et al. 2006), and the values were $1.13628 \times 10^{-11} \mathrm{~m}^{2}, 1.1179 \times 10^{-11} \mathrm{~m}^{2}, 1.11382 \times 10^{-11} \mathrm{~m}^{2}$ and $1.09365 \times 10^{-11} \mathrm{~m}^{2}$ for ZZPO, ZZP1, ZZP2 and ZZP3, respectively.

The porosity of the plant fibers decreased with the increase of glycerol content (Fig. 5b), and the decline of macroporous proportion and porosity (Fig. 5c) caused the permeability reduction. These factors led to the rise in the water diffusion resistance of the plant fibers increased during the water vapor adsorption.

\section{Effect of glycerol on the water state of plant fibers}

2D LF-NMR relaxation spectra reflect the change of water state and distribution (Melo et al., 2021) in the plant fibers caused by glycerol during the water vapor adsorption, SR-CPMG sequence was applied to capture $2 \mathrm{D} \mathrm{T}_{1}-\mathrm{T}_{2}$ maps of the samples. Three main water states in plant fibers could be distinguished clearly, according to $T_{2} . T_{21}$ in the range of $0.02-10 \mathrm{~ms}$ was assigned as bound water (strongly adsorbed water), $\mathrm{T}_{22}$ 10-80 ms as immobile water, and $\mathrm{T}_{23}>100 \mathrm{~ms}$ as free water (Wang et al. 2020b; Yang et al. 2020).

ZZPO in dry state presented a small amount of bound water (Fig. 6a), which $\mathrm{T}_{21}$ was $0.21-2.5 \mathrm{~ms}$. As water vapor adsorption time extended, bound water and free water coexisted in ZZP0, the former was given priority. Figure $6 \mathrm{~b}$ presented that there were bound water mainly $\left(T_{21} 0.21-2.5 \mathrm{~ms}\right)$, free water partially ( $T_{23} 80-193 \mathrm{~ms}$ ) when ZZPO achieved to moisture adsorption equilibrium. This result was similar to other biomass and porous media for water vapor adsorption (Wang et al. 2020b). 
ZZP3 showed differences in water state and its distribution compared with ZZP0 at dry state. Glycerol affected the interaction between water molecules with the plant fibers for ZZP3. The proton signal of glycerol and fibrous matrix overlapped partly due to the interaction between them, and merely bound water ( $T_{21}$ 0.021-3.5 ms) existed in ZZP3 at the dry state (Fig. 7a). The outstanding hydrophilicity of glycerol was proved according to Fig. $7 \mathrm{~b}$, indicating that the proton signals of glycerol and immobile water were indivisible when ZZP3 attained moisture adsorption equilibrium. Even the WHC of the samples improved significantly, there was no free water existing in the plant fibers loaded with glycerol.

Figure 8a declared that there was a small amount of water left in per sample and the $M C$ was proportional to the content of glycerol at the dry state. ZZPO demonstrated the lowest intensity, and $T_{21}$ $0.21-2.5$ ms represented bound water only, while the other samples contained bound water and immobile water mixed with glycerol whose intensity was detected at $\mathrm{T}_{22} 10-35 \mathrm{~ms}$.

The amount of bound water heightened with the increase of glycerol content, while their immobile water decreased. With the time of moisture adsorption extended at $25^{\circ} \mathrm{C}$ and $80 \% \mathrm{RH}, \mathrm{T}_{2}$ relaxation spectra of the four samples were shown in Figs. 8b-f respectively. The peak area of $\mathrm{T}_{22}$ (immobile water mixed with glycerol) accounted for a major proportion and the amount of immobile water increased significantly, while the corresponding peak area of $\mathrm{T}_{21}$ (bound water) was much less and increased slowly. With the $\mathrm{MC}$ of the samples enhanced, the value of relaxation time $\mathrm{T}_{22}$ shifted to the right, especially for the high glycerol content samples ZZP2 and ZZP3. When the immobile water closed to the saturation point, the peak area of $T_{22}$ moved towards stability, and that of $T_{21}$ gradually enlarged until the moisture adsorption equilibrium was achieved. The result indicated the adsorption of bound water responded behind immobile water for the plant fibers added with glycerol. When ZZPO reached its moisture adsorption equilibrium, the free water distribution pattern of $T_{23}$ could be monitored (Fig. 8f), while no free water signal appeared in ZZP1-3. We postulated that water molecules entered the plant fibers with glycerol as immobile water preferentially during the water vapor adsorption, and when the immobile water was closed to the saturation, part of them became bound water, simultaneously external water molecules supplemented the vacancy of immobile water until the bound and immobile water were saturated. During the whole adsorption process, the bound and immobile water were the main forms of water molecules for the plant fibers loaded with glycerol.

\section{Moisture adsorption mechanisms of plant fiber before and after loading with glycerol}

Figure 9 illustrates the moisture adsorption behavior during the transfer of water molecules in ZZPO and ZZPX loaded with an amount of glycerol. Comparing with ZZPO, glycerol decreased the porosity and Crl of the plant fibers, enlarged the amorphism region and increased the active adsorption sites due to intraand inter-molecular hydrogen bonds for ZZPX. As a consequence, glycerol enhanced the $M C_{e}$ of the plant fibers. However, it strengthened the moisture transport resistance (Alak et al. 2000), and caused a decrease of $D_{\text {eff }}$ 
For ZZP0, as the moisture adsorption time extended, the water molecules entered the surface and amorphous zone (Stevanic and Salmén, 2019) of the plant fibers and transformed into bound water, simultaneously part of the water existed in the macropore or on the surface of ZZPO as free water. For ZZPX, water molecules entered the plant fibers as the immobile water preferentially, due to the hydrogen bond interaction between glycerol and water molecules. When the immobile water tended to be saturated, part of the immobile water acted with the amorphous zone of the plant fibers and transformed into bound water, simultaneously external water molecules supplemented the vacancy of immobile water until the bound and immobile water were both saturated due to the hydrogen bond interaction between glycerol and water molecules.

\section{Conclusions}

The moisture adsorption sites of a plant-based composite fiber material were enhanced by glycerol loading, while the water diffusion resistance increased simultaneously. Glycerol also affected the water sates and the distributions in the plant fibers. Water molecules entered the plant fibers with glycerol as immobile water preferentially during the moisture adsorption, when the immobile water tended to be saturated, part of the immobile water transformed into bound water, simultaneously external water molecules supplemented the vacancy of immobile water, none of free water appeared. The research outcome expands the knowledge on moisture adsorption behavior of the plant-based fibers and their modification by adding humectants.

\section{Declarations}

Acknowledgements

The authors are extremely grateful for Dr Jiashi Wang and the engineer Danli He and Qi Zhou for their technical supports. At the same time, the authors take this opportunity to thank Dr Xiaolei Zhang and Dr Chuan Liu for providing language help.

Funding

This work was supported by the Postdoctoral Program of Zhengzhou Tobacco Research Institute of CNTC (China) and Fundamental Research Program of China Tobacco Yunnan Industrial Co. Ltd (2021XY01).

Declaration of Competing Interest

The authors declare no conflict of interest.

Supplementary data

Supplementary data for this work can be found in e-version of this paper online. 
Author information

Affiliations

Zhengzhou Tobacco Research Institute of CNTC, 450001, Zhengzhou, China

Lili Fu, Ke Zhang, Mingjian Zhang, Le Wang, Yue Sun, Feng Huang, Shuang Wang, Qi Zhang, Bing Wang, Bin Li, Zhongya Guo

China Tobacco Hebei Industrial Co. Ltd, 050051, Shijiazhuang, China

Songjin Zheng

China Tobacco Yunnan Industrial Co. Ltd, 650202, Kunming, China

Ze Liu, Shanzhai Shang

Guangzhou Institute of Energy Conversion, Chinese Academy of Sciences, 510640, Guangzhou,China

Lili Fu, Yan Cao

Corresponding author

Correspondence to Zhongya Guo.

Author Contributions Statement

Conceptualization: Lili Fu and Yan Cao; Investigation, methodology: Lili Fu, Zhongya Guo, Ke Zhang and Yue Sun; Experiment: Songjin Zheng, Ze Liu and Shaizhai Shang; Writing-original draft preparation: Lili Fu; Writing-review \& editing: Mingjian Zhang, Feng Huang, Shuang Wang and Qi Zhang; Supervision: Bing Wang, Bin Li and Yan Cao.

\section{References}

1. Alak B, Hari R, Bandru R, Siddharth C (2000) Moisture sorption response of paper subjected to ramp humidity changes: modeling and experiments. Industrial and Engineering Chemistry Research 39:219-226. https://doi.org/10.1021/ie990279w

2. Bu X, Pei J C, Zhang FD, Liu HT, Zhou ZM, Zhen XQ, et al (2018) The hydration mechanism and hydrogen bonding structure of 6-carboxylate chitooligosaccharides superabsorbent material prepared by laccase/TEMPO oxidation system. Carbohydrate Polymers 188:151-158. https://doi.org/10.1016/j.carbpol.2018.01.099

3. Chen DY, Zheng Y, Zhu XF (2012) Determination of effective moisture diffusivity and drying kinetics for poplar sawdust by thermogravimetric analysis under isothermal condition. Bioresource Technology 107:451-455. https://doi.org/10.1016/j.biortech.2011.12.032 
4. Dereka B, Yu Q, Lewis NHC, Carpenter WB, Bowman JM, Tokmakoff, A (2021) Crossover from hydrogen to chemical bonding. Science 371:160-164. https://doi.org/10.1126/science.abe1951.PMID:33414217

5. Emerson RM, Hernandez S, Williams CL, Hartley DS (2018) Improving bioenergy feedstock quality of high moisture short rotation woody crops using air classification. Biomass and Bioenergy 117:56-62. https://doi.org/10.1016/j.biombioe.2018.07.015

6. Fredriksson M, Thybring EE (2018) Scanning or desorption isotherms? Characterising sorption hysteresis of wood. Cellulose 25:4477-4485. https://doi.org/10.1007/s10570-018-1898-9

7. French AD, Cintrón MS (2013) Cellulose polymorphy, crystallite size, and the Segal Crystallinity Index. Cellulose 20:583-588. https://doi.org/10.1007/s10570-012-9833-y

8. French AD (2014) Idealized powder diffraction patterns for cellulose polymorphs. Cellulose 21:885896. https://doi.org/10.1007/s10570-013-0030-4

9. French AD (2020) Increment in evolution of cellulose crystallinity analysis. Cellulose 27:54455448. https://doi.org/10.1007/s10570-020-03172-z

10. Garg M, Apostolopoulou-Kalkavoura V, Linares M, et al (2021) Moisture uptake in nanocellulose: the effects of relative humidity, temperature and degree of crystallinity. Cellulose (published on line) . https://doi.org/10.1007/s10570-021-04099-9

11. Gheorghita R, Gutt G, Amariei S (2020) The use of edible films based on sodium alginate in meat product packaging: an eco-friendly alternative to conventional plastic materials. Coatings 10:166. https://doi.org/10.3390/coatings 10020166

12. Guo GF, Li B, Liu CX, Jin X, Wang ZG, Ding MZ, et al (2019) Characterization of moisture mobility and diffusion in fresh tobacco leaves during drying by the TG-NMR analysis. Journal of Thermal Analysis and Calorimetry 135:2419-2427. https://doi.org/10.1007/s10973-018-7312-x

13. Guo X, Wu Y, Xie X (2017) Water vapor sorption properties of cellulose nanocrystals and nanofibers using dynamic vapor sorption apparatus. Scientific Reports 7:1-12. https://doi.org/10.1038/s41598017-14664-7

14. Halter HM. Ito TI (1972) Reconstituted tobacco-smoking and health possibilities. Journal of the National Cancer Institute 48:1869-1883.

15. Hachem ZE, Célino A, Challita G, Branchu S, Duigou AL, Fréour S (2020) Dimensional variation and evolution of mechanical properties of wet aged composites reinforced with flax fibers. Journal of Composite Materials 0:1-18. https://doi.org/10.1177/0021998320966045

16. Hofstetter K, Hinterstoisser B, Salmén L (2006) Moisture uptake in native cellulose-the roles of different hydrogen bonds: a dynamic FT-IR study using Deuterium exchange. Cellulose 13:131145. https://doi.org/10.1007/s10570-006-9055-2

17. Jiang L, Wu N, Zheng A, Liu A, Zhao Z, Zhang F, et al (2017) Comprehensive utilization of hemicellulose and cellulose to release fermentable sugars from corncobs via acid hydrolysis and fast pyrolysis. ACS Sustainable Chemistry \& Engineering 5:5208-5213. https://doi.org/10.1021/acssuschemeng.7b00561 
18. Hill CAS, Norton A, Newman G (2009) The water vapor sorption behavior of natural fibers. Journal of Applied Polymer Science 112:1524-1537. https://doi.org/10.1002/app.29725

19. Hill CAS, Norton A, Newman G (2010) The water vapour sorption properties of Sitka spruce determined using a dynamic vapour sorption apparatus. Wood Science and Technology 44:497-514. https://doi.org/10.1007/s00226-010-0305-y

20. Jiang XX, Zhai R, Jin MJ (2021) Increased mixing intensity is not necessary for more efficient cellulose hydrolysis at high solid loading. Bioresource Technology 329:1-10. https://doi.org/10.1016/j.biortech.2021.124911

21. Joardder M, Mourshed M, Masud MH (2019) Correction to: state of bound water: measurement and significance in food processing. (eBook). Spring, pp 47-76.

22. Kolbuk D, Jeznach O, Wrzecionek M, Gadomska-Gajadhur A (2020) Poly (glycerol succinate) as an eco-friendly component of PLLA and PLCL fibres towards medical applications. Polymers 12:112. https://doi.org/10.3390/polym 12081731

23. Liu W, Fan AW, Huang XM (2006) Theory and application of heat and mass transfer in porous media, 1st ed. Science Press, Beijing, pp 7-15.

24. Lorenzo MO, Haq S, Bertrams T, Murray P, Baddeley CJ (1999) Creating chiral surfaces for enantioselective heterogeneous catalysis: r,r-tartaric acid on $\mathrm{Cu}(110)$. The Journal of Physical Chemistry B 103:10661-10669. https://doi.org/10.1021/jp992188i

25. Lovikka VA, RautkariL, Maloney TC (2018) Changes in the hygroscopic behavior of cellulose due to variations in relative humidity. Cellulose 25:87-104. https://doi.org/10.1007/s10570-017-1570-9

26. Melo RQC, Fook MVL, Lima AGB (2021) Non-Fickian moisture absorption in vegetable fiber reinforced polymer composites: the effect of the mass diffusivity. Polymers 13:1-

30. https://doi.org/10.3390/polym13050761

27. Montrazi ET, Lucas-Oliveira E, Araujo-Ferreira AG, Barsi-Andreeta M, Bonagamba TJ (2018) Simultaneous acquisition for $\mathrm{T}_{2}-\mathrm{T}_{2}$ exchange and $\mathrm{T}_{1}-\mathrm{T}_{2}$ correlation NMR experiments. Journal of Magnetic Resonance 289:63-71. https://doi.org/10.1016/j.jmr.2018.02.008

28. Modaressi H, Garnier G (2002) Mechanism of wetting and absorption of water droplets on sized paper: effects of chemical and physical heterogeneity. Langmuir 18:642649. https://doi.org/10.1021/la0104931

29. Pei JC, Ping QW (2012) Lignocellulosic chemistry, 4th ed. China Light Industry Press, Beijing, pp 1-56.

30. Penttilä PA, Altgen M, Carl N, et al (2020) Moisture-related changes in the nanostructure of woods studied with X-ray and neutron scattering. Cellulose 27:71-87. https://doi.org/10.1007/s10570-01902781-7

31. Sanders JM, Misra M, Mustard TJL, Giesen DJ, Zhang T, Shelley J, et al (2021). Characterizing moisture uptake and plasticization effects of water on amorphous amylose starch models using molecular dynamics methods. Carbohydrate Polymers 252:1-

11. https://doi.org/10.1016/j.carbpol.2020.117161

Page $14 / 22$ 
32. Perrier A, Touchard F, Chocinski-Arnault L, Mellier D (2017) Influence of water on damage and mechanical behaviour of single hemp yarn composites. Polymer Testing 57:17-25.

33. Popescu CM, Hill CAS, Curling S, Ormondroyd G, Xie YX (2014) The water vapour sorption behaviour of acetylated birch wood: how acetylation affects the sorption isotherm and accessible hydroxyl content. Journal of Materials Science 49:2362-2371. https://doi.org/10.1007/s10853-013-7937-x

34. Ridzuan MJM, Abdul MMS, Afendi M, Azduwin K, Amin NAM, Zahri JM, et al (2016) Moisture absorption and mechanical degradation of hybrid pennisetum purpureum glass-epoxy composites. Composite Structures 141:110-116. https://doi.org/10.1016/j.compstruct.2016.01.030

35. Sotannde OA, Dadile AM, Umar M, Idoghor SM, Zira BD (2020) Effect of fuel material compositions on combustion properties of wood chips from smallhold farm plots in a sudano-sahelian environment of nigeria. Current Journal of Applied Science and Technology 39:93-104. https://doi.org/10.9734/cjast/2020/v39i230502

36. Stevanic JS, Salmén L (2020) Molecular origin of mechano-sorptive creep in cellulosic fibres. Carbohydrate Polymers 230:1-6. https://doi.org/10.1016/j.carbpol.2019.115615

37. Sun Y, He Z, Tu R, Wu Y, Jiang E, Xu X (2019) The mechanism of wet/dry torrefaction pretreatment on the pyrolysis performance of tobacco stalk. Bioresource Technology 286:1-12. https://doi.org/10.1016/j.biortech.2019.121390

38. Taniguchi T, Harada H, Nakato K (1978) Determination of water adsorption sites in wood by a hydrogen-deuterium exchange. Nature 272:230-231. https://doi.org/10.1038/272230a0

39. Varara AK, Korneliya G, Nathalie L, Lennart B (2018) Thermal conductivity of hygroscopic foams based on cellulose nanofibrils and a nonionic polyoxamer. Cellulose 25:11171126. https://doi.org/10.1007/s10570-017-1633-y

40. Wang H, Cui H, Wang X, Lin C, Zhang X (2020a) Metal complexed-enzymatic hydrolyzed chitosan improves moisture retention of fiber papers by migrating immobilized water to bound state. Carbohydrate Polymers 115967:1-10. https://doi.org/10.1016/j.carbpol.2020.115967

41. Wang J, Li Y, Wang Z, Li Y, Liu N (2016) Influence of pretreatment on properties of cotton fiber in aqueous $\mathrm{NaOH} /$ urea solution. Cellulose 23(3): 2173-2183. https://doi.org/10.1007/s10570-0160938-6

42. Wang SQ, Lin R, Cheng SS, Tan MQ (2020b) Water dynamics changes and protein denaturation in surf clam evaluated by two-dimensional LF-NMR $\mathrm{T}_{1}-\mathrm{T}_{2}$ relaxation technique during heating process. Food Chemistry 320:1-8. https://doi.org/10.1016/j.foodchem.2020.126622

43. Yamamoto Y, Fujieda $T$, Ichiura $H$ (2020) Reforming paper structure using an ionic liquid treatment to improve the specific surface area, moisture retention, and hydrophobicity. Cellulose 27:8317-8327. https://doi.org/10.1007/s10570-020-03303-6

44. Yang Q, Sun PZ, Fumagalli L, Stebunov YV, Haigh SJ, Zhou ZW, et al (2020) Capillary condensation under atomic-scale confinement. Nature 588:250-253. https://doi.org/10.1038/s41586-020-2978-1

45. Yang J, Yang S, Duan YX, Tian YF, Zhao W (2015) Investigation of thermogravimetry and pyrolysis behavior of tobacco material in two heat-not-burn cigarette brands. Acta Tabacaria Sinica 21:7- 
13. http://doi.org/10.16472/j.chinatobacco.2015.070

46. Yao W, Weng Y, Catchmark JM (2020) Improved cellulose X-Ray diffraction analysis using Fourier series modeling. Cellulose 27:5563-5579. https://doi.org/10.1007/s10570-020-03177-8

47. Zhang X, Li J, Yu Y, Wang H (2018) Investigating the water vapor sorption behavior of bamboo with two sorption models. Journal of Materials Science 53:8241-8249. https://doi.org/10.1007/s10853018-2166-y

48. Zheng S, Li T, Li Y, Shi Q, Wu F (2017) Novel 1H NMR relaxometry methods to study the proton distribution and water migration properties of tobacco. Analytical Methods 9:1741-1747. https://doi.org/10.1039/c6ay03242g

\section{Figures}
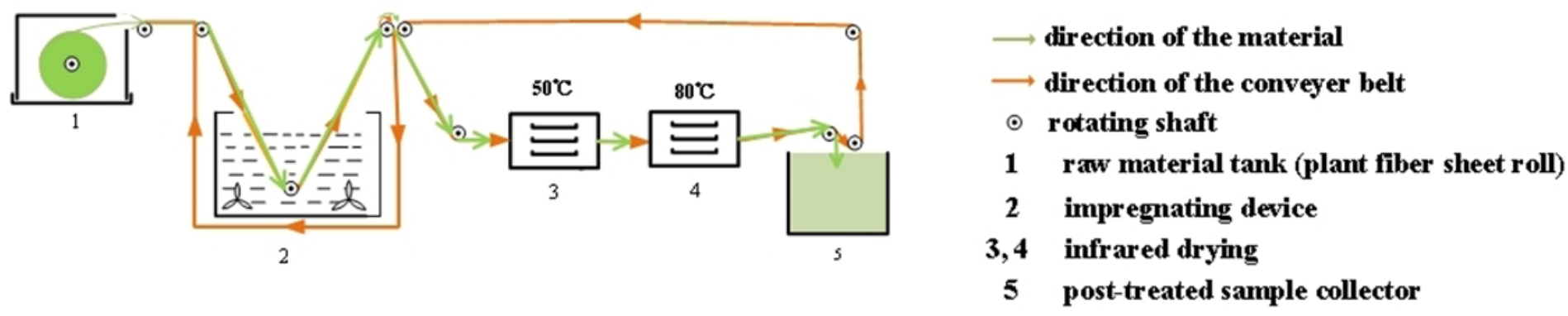

Figure 1

The experimental set-up used for drying and impregnating device
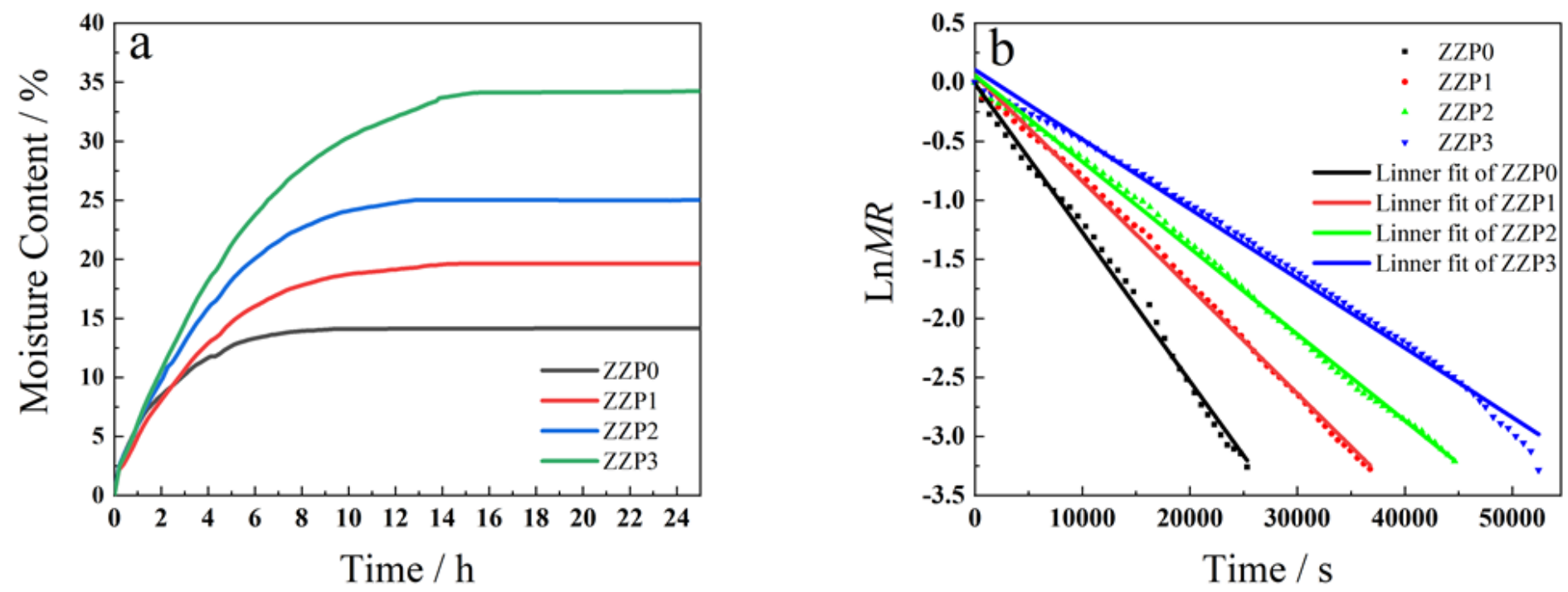

Figure 2

Moisture adsorption curves of the samples (a) and correlation between $\operatorname{Ln}(\mathrm{MR})$ and the adsorption time (b) 

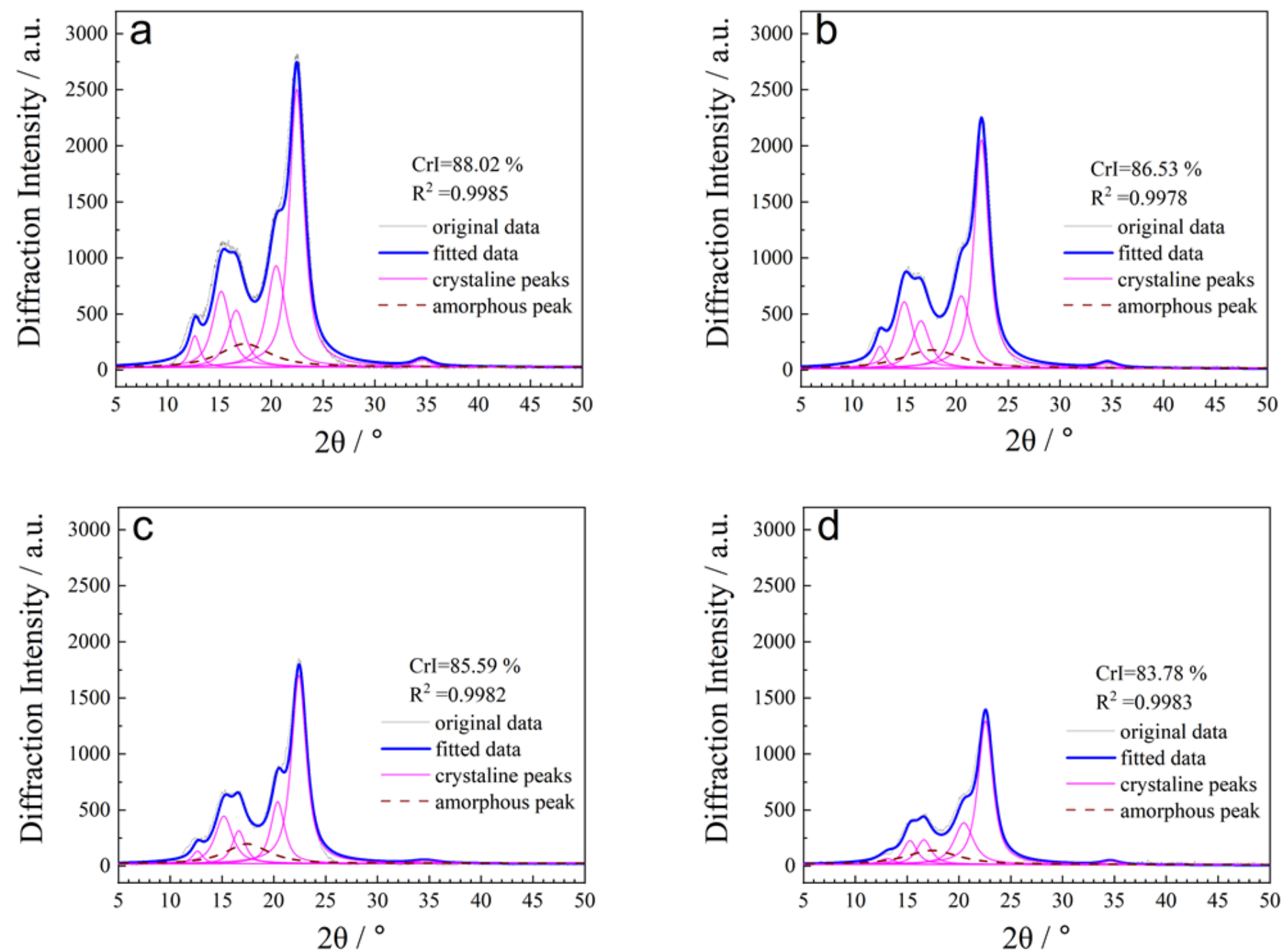

Figure 3

Peak deconvolution of the plant fiber samples XRD data: (a) ZZP0; (b) ZZP1; (c) ZZP2; (d) ZZP3
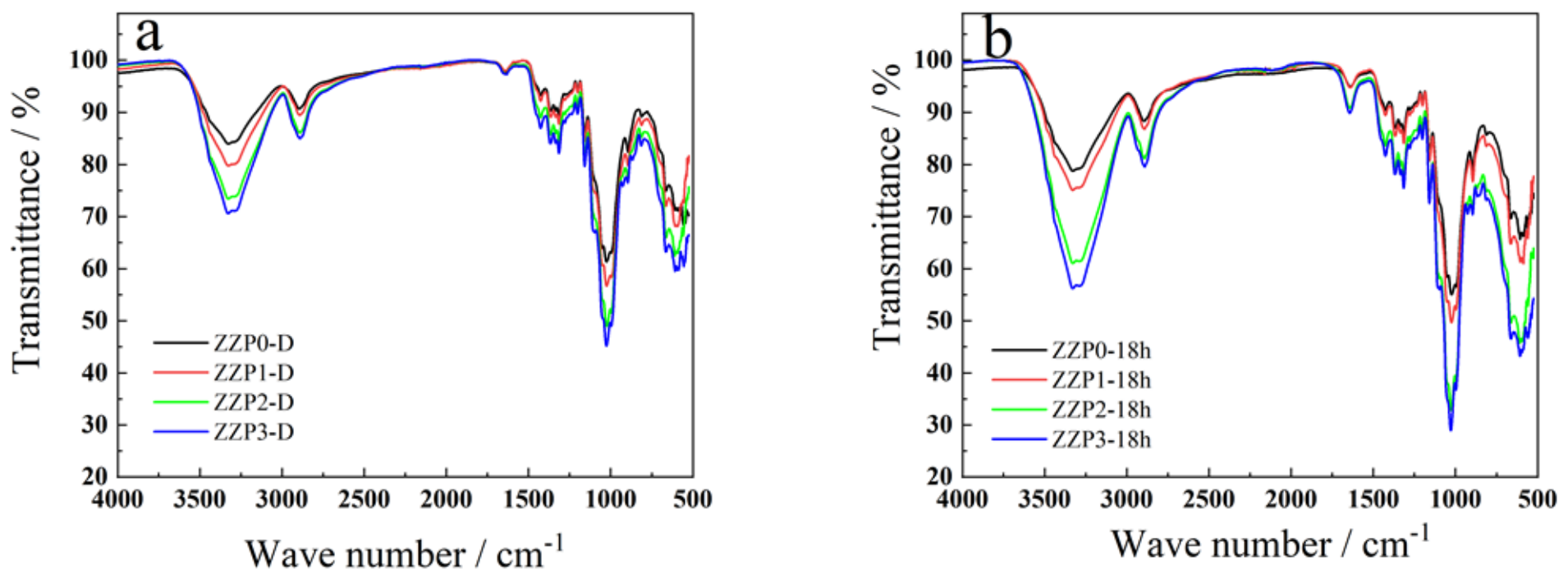
Figure 4

IR spectra of the dried (a) and hygroscopic (b) plant fiber samples
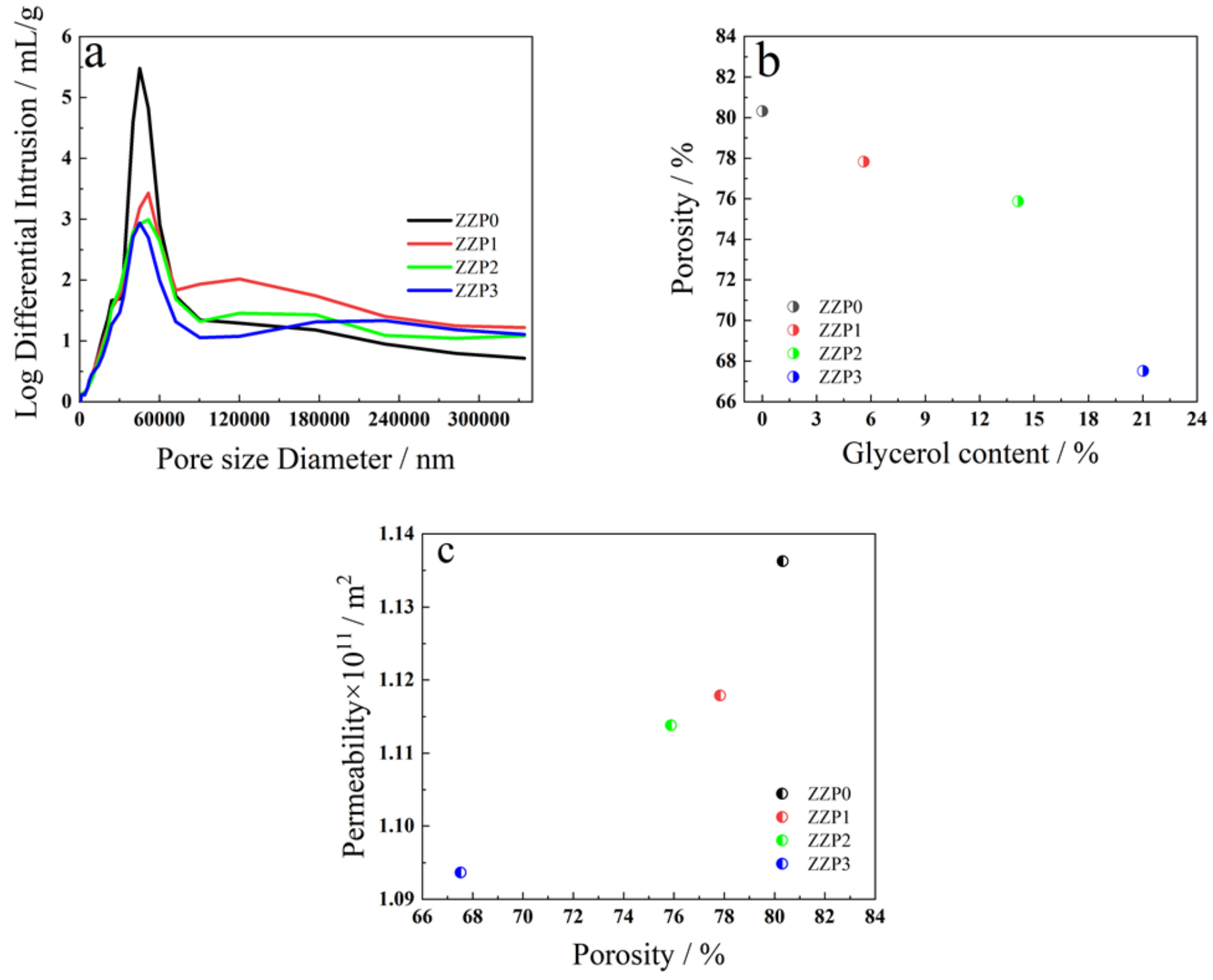

Figure 5

The aperture distribution of the samples (a); the relationship between the porosity and glycerol content (b); the relationship between the permeability and the porosity (c) 

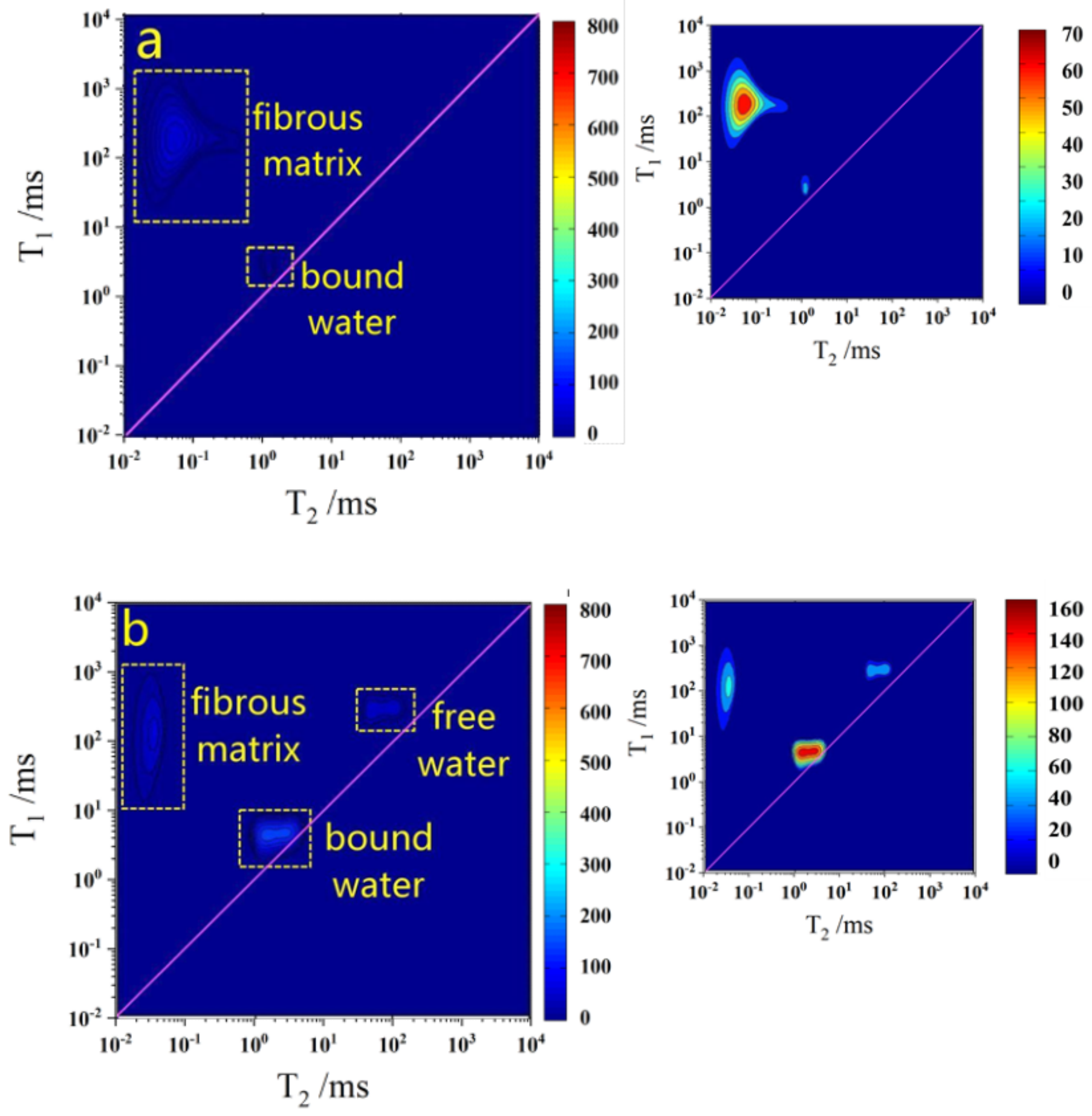

Figure 6

2D LF-NMR T1-T2 correlation relaxation spectra of ZZPO (a) after drying treatment at $80{ }^{\circ} \mathrm{C}, 0 \% \mathrm{RH}$, for 2 h; (b) after hygroscopic treatment at $25^{\circ} \mathrm{C}, 80 \% \mathrm{RH}$, for $18 \mathrm{~h}$. Insets showed the clear figure by adjusting the range of each diagram. $T 2$ relaxation time is given in $\mathrm{X}$ axis and $\mathrm{T} 1$ relaxation time in $\mathrm{Y}$ axis 

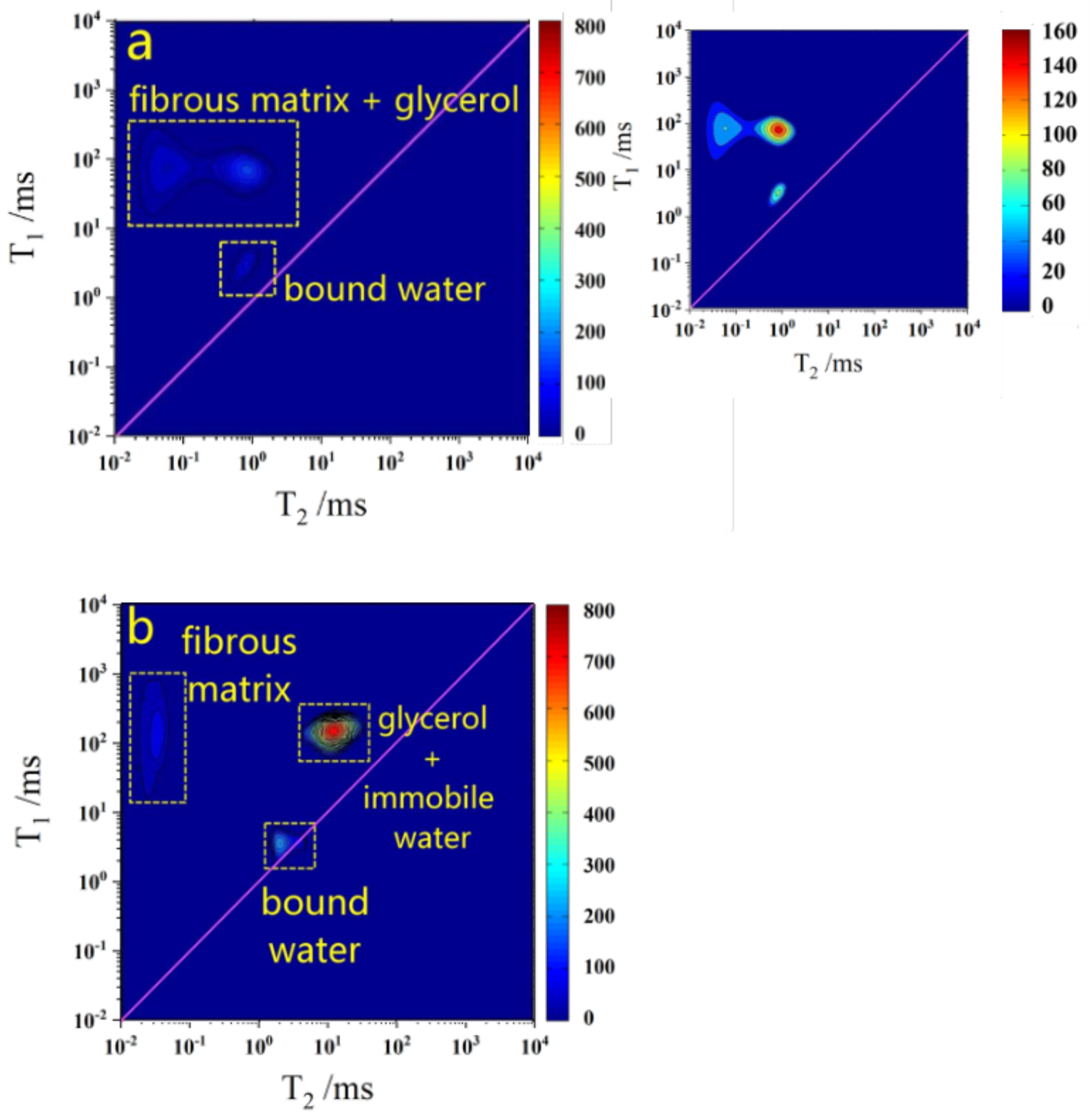

Figure 7

2D LF-NMR T1-T2 relaxation spectra of ZZP3 (a) after drying treatment at $80{ }^{\circ} \mathrm{C}, 0 \% \mathrm{RH}$, for $2 \mathrm{~h}$; (b) after hygroscopic treatment at $25{ }^{\circ} \mathrm{C}, 80 \% \mathrm{RH}$, for $18 \mathrm{~h}$. Inset showed the clear figure by adjusting the corresponding range of diagram 

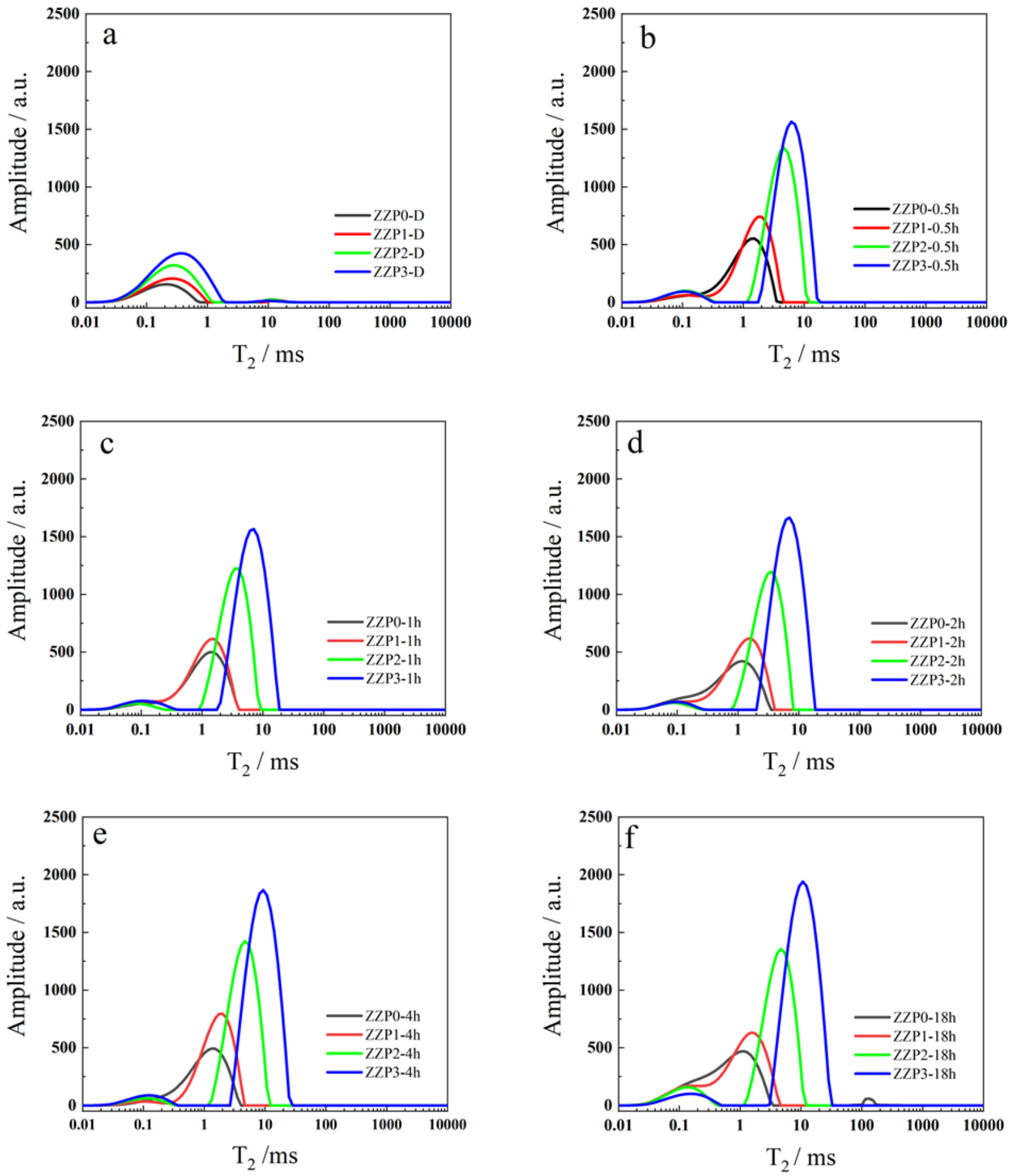

\section{Figure 8}

T2 relaxation spectra of the plant fiber samples after different treatments (a) drying treatment at $80^{\circ} \mathrm{C}$, $0 \% \mathrm{RH}$, for $2 \mathrm{~h}$; (b) - (f) water vapor adsorption at $25^{\circ} \mathrm{C}, 80 \% \mathrm{RH}$, for different time 


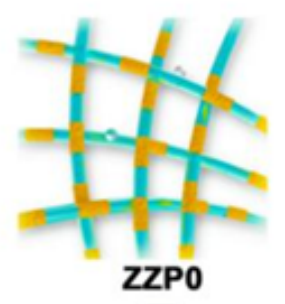

Surface-modified with glycerol

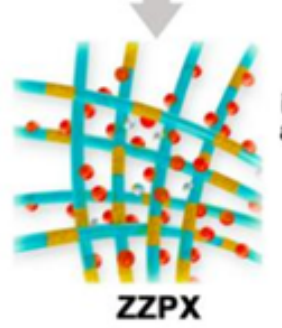

Bound $\mathrm{H}_{2} \mathrm{O}$

i. moisture adsorption
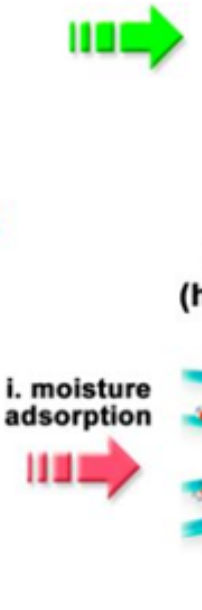

Immobile $\mathrm{H}_{2} \mathrm{O}$ (hydrogen bond)

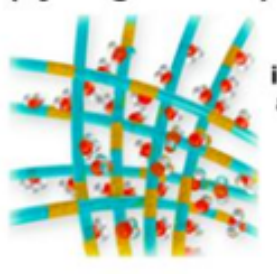

Bound $\mathrm{H}_{2} \mathrm{O}+$ immobile $\mathrm{H}_{2} \mathrm{O}$

Bound $\mathrm{H}_{2} \mathrm{O}+$ free $\mathrm{H}_{2} \mathrm{O}$

ii. adsorption equilibrium
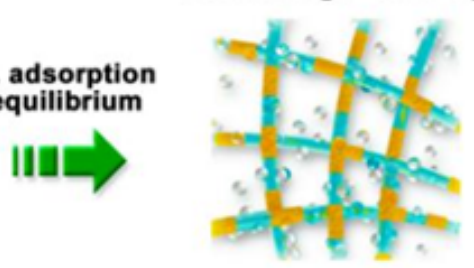

ii. transfering into amorphism region
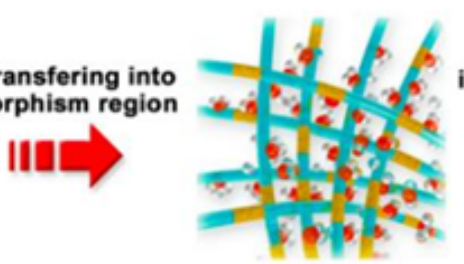

5. $\mathrm{H}_{2} \mathrm{O}$ molecule

- Glycerol molecule

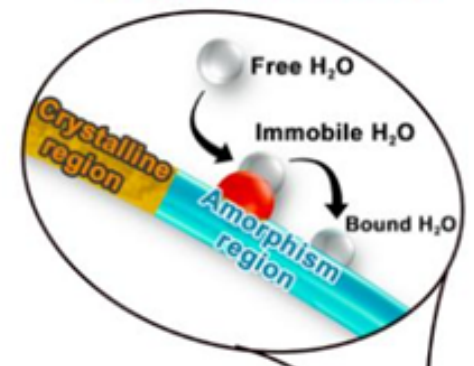

adsorption equilibrium (no free $\mathrm{H}_{2} \mathrm{O}$ existed)

III

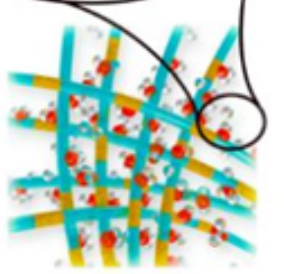

Figure 9

The moisture adsorption process of the plant fibers before and after loading with glycerol

\section{Supplementary Files}

This is a list of supplementary files associated with this preprint. Click to download.

- Supplementarydata.docx 